\title{
A PROSPECTIVE STUDY FOR EVALUATING VISUAL INSPECTION AFTER ACETIC ACID (VIA) AND LUGOLS IODINE (VILI) APPLICATION IN SCREENING OF PREMALIGNANT LESIONS OF CERVIX
}

Kalpana Yadav, Monika Patidar, Meena Bhargava

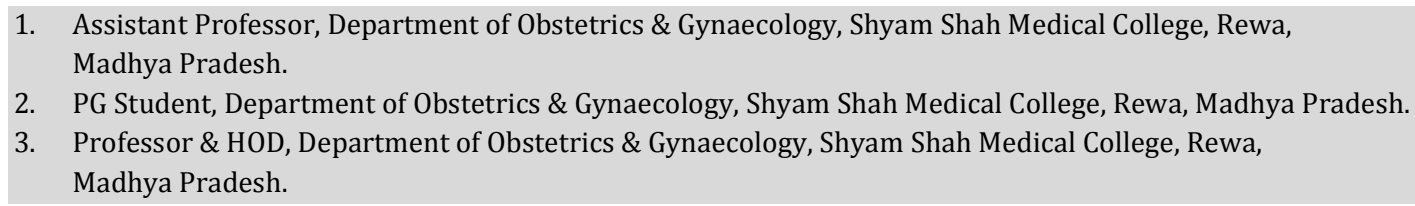

\section{CORRESPONDING AUTHOR}

Dr. Kalpana Yadav

Assistant Warden quarter,

Shrishthi Girls Hostel,

Hospital Campus, Rewa, Madhya Pradesh,

E-mail: sshabd@yahoo.com

Ph: 00919907561996.

ABSTRACT: AIMS AND OBJECTIVES: To evaluate the potential of VIA \& VILI in the screening of preinvasive and invasive lesions in unhealthy cervix and comparing them with colposcopy guided biopsy thereby determining its usefulness in screening. Also to evaluate the correlation of demographic data like age, socioeconomic status, education, residential area, parity, age at marriage, use of various contraceptive methods in premalignant lesions of cervix. METHODS STUDY was conducted on 200 symptomatic and asymptomatic women with abnormal cervices who attended outdoor department of SSMC associated hospital SGMH. All cases were subjected to Pap smear, VIA, VILI and colposcopy, women with premalignant lesion were subjected to directed biopsy from suspicious areas and sent for histopathological examination (HPE). Results of Pap smear, VIA, VILI and colposcopy are compared to HPE report. OBSERVATIONS: On cytology $27.5 \%$ of cases had LSIL \& HSIL. All were positive by VIA \& VILI, of which $80 \%$ had dysplasia on biopsy. On colposcopy, incidence of CIN was 38.5\%. all were positive on VIA \& VILI, out of which, $76.6 \%$ were proved dysplastic on colposcopy guided biopsy. VIA when compared with HPR had sensitivity \& specificity of $80 \%$ \& $67 \%$ respectively, while that of VILI was found to be $80 \%$ \& $87 \%$ respectively. CONCLUSION: VIA \& VILI are simple, inexpensive, low technology test. Both when combined has high sensitivity as well as specificity. This can be practiced by clinicians and paramedics on wide scale. Another advantage is immediate availability of results, so that treatment can be started during same visit.

KEY WORDS: Visual inspection after application acetic acid, visual inspection after application Lugol's Iodine, colposcopy, cervical intraepithelial lesion, screening, Pre-malignant lesions.

INTRODUCTION: Worldwide cervical cancer is the second most common cancer among women with an estimated 4,93,000 new cases occurring annually and 2,74,000 deaths each year. According to ICMR, cancer cervix incidence in India varies from 20 to 35 per 1,00,000 women of age group 35 to 65 years, while in developed countries it is as low as 1 to 8 per 1,00,000 women[1].

An important reason for the high incidence of cervical cancer in developing countries is the lack of effective screening program to detect precancerous lesion and treat before it 
progresses to invasive cancer. Various screening methods are available such as cytology, colposcopy and directed biopsy, but not feasible to implement in a country like India, due to restrictions on availability of infrastructure, resources and funding. This has led to development of low cost technologies such as down staging by naked eye visual inspection, VIA, VILI that can be easily taught to and practiced by paramedical personnel in the remote areas of the country. [2].

Purpose of this study is to evaluate the potential of VIA \& VILI in the screening of preinvasive and early invasive lesions in unhealthy cervices which may be confirmed by colposcopy guided biopsy thereby evaluating its usefulness in screening.

MATERIALS AND METHODS: The present study was conducted on 200 women with abnormal cervices in the department of Obstetrics and Gynaecology, Shyam Shah Medical College and associated Gandhi Memorial Hospital (G.M.H.), Rewa (M.P.), from May 2010 to October 2011(18 month).Women above 16 years of age with varied parity and socioeconomic status who attended OPD with following criteria were included in the study : (i) suspicious symptoms like vaginal or cervical discharge, post coital, intermenstrual or postmenopausal bleeding, (ii)suspicious cervices e.g.; hypertrophied unhealthy, eroded, torn or bleeds on touch (iii) abnormal cytology report in healthy cervices. Exclusion criteria were pregnancy, vaginitis, patients in menses, post hysterectomy, obvious cervical growth at the time of examination, and post irradiation.

On first visit, complete history including demographic data like age, socioeconomic status, education, residential area, parity, age at marriage, use of various contraceptive methods was taken and per speculum examination was done. If required, material collected for cytology and sent for examination. VIA, VILI was performed after counseling and consent. Examination was done with naked eye, then $5 \%$ freshly prepared acetic acid solution was applied and acidowhiteness was studied after one minute of application. Then Lugol's iodine was applied and colour change was noted as negative areas, mustard yellow or brown. Then all cases were subjected to colposcopy. For colposcopic examination colposcope model 150 FC with magnification between $10 \mathrm{X}$ to $12.5 \mathrm{X}$ was used.

Colposcopy was termed satisfactory when squamo-columnar junction was completely visible and borders of all lesions were well defined. According to findings of VIA, VILI \& colposcopy grading of CIN was done by modified Reid's scoring system. Biopsy was taken from suspicious lesions on colposcopy finding were then compared with HPR and statistical analysis was done.

OBSERVATIONS \& RESULTS: 200 women were enrolled in the study. The demographic characteristics of the women are presented in table 1

DISCUSSION: Widespread use of Pap smear has achieved drastic reduction in incidence and mortality of cervical cancer in USA, Canada \& Europe $^{6}$. Poor sensitivity (29-56\%) of conventional cytology has been overcome in developed countries by using liquid based thin layer cytology and use of highly specific HPV DNA testing?.

This protocol is almost nonexistent in resource poor settings. VIA \& VILI are low cost objective methods which do not require any extra equipment or laboratory back up. It can also be practiced by paramedical workers and nurses after proper training. 
Main advantage of VIA \& VILI is immediate availability of results, making it possible to institute further investigation for test positive women, as well as plan the treatment during the same visit, so called " screen and treat" approach. Hence cost effectively and moreover could be the compliance for treatment is crucial to bring down the incidence and mortality due to cervical cancer.

Colposcopic magnification is a complimentary method to VIA \& VILI and not essential to identify a cervix with higher grade lesion. VIA \& VILI can also guide a practicing gynaecologist regarding the site to be biopsied.

Beside in the absence of organized cytology screening program and limited availability of Colposcopy facilities VIA \& VILI can be propagated on a wider scale.

The presenting complaint was vaginal discharge in 154, pain in abdomen in 38 , menstrual irregularity in 44 , itching in private parts in 35 , post-coital bleeding in 19 , postmenopausal bleeding in 16 women \& asymptomatic women were 30 . Maximum cases $(61.5 \%)$ were from rural areas.

Pap smear, VIA, VILI, colposcopy results were available of all 200 cases while that of biopsy in 136 women in whom biopsy was indicated. Results of pap smear were statistically correlated with VIA and VILI as shown in table 2.

\section{REFERENCES:}

1. Ferly J, Parkin DM, Pisani P, GLOBOCAN 2002: Cancer incidence, mortality and prevalence worldwide version 1.0 IARC Cancer Base No. 5, Lyon: IARC Press. 2005.

2. Lunt R. Worldwide early detection of cervical cancer. Obstetrics and Gynecology 1984; 63:708-13.

3. Sankarnarayanan R, Wesley R, Thara S, Dhakad N, Chandralekha B, Sebastian P, Chithrathara K, Parkin DM, Nair MK. Int J Cancer. 2003 Sep 1; 106 (3): 404-8.

4. S Qureshi, V Das, F Zahna et al. Evaluation of visual inspection with acetic acid and Lugol's iodine as cervical cancer screening tools in a low resource setting. The Royal Society of Medicine Press United. Jan 2010; (40): 9- 12.

5. Shastri SS, Dinshaw K, Amin G et al. Concurrent evaluation of visual, cytological and HPV testing as screening methods for the early detection of cervical neoplasia in Mumbai, India. Bull WHO 2005; 83; 186- 94.

6. Johnson C. Conventional cytology. In: Apgar BS, Brotzman GL, Spitzer M (eds). Colposcopy principles and practice. An integrated textbook and atlas. Philadelphia, WB. Sounders Company 2002; 52-

7. Catterina F, Julia G. Critical Review. In; Visual inspection of uterine cervix with acetic acid (VIA): A critical review and selected articles. Washington DC. Pan American Health Organization (PAHO) 2003: 8. 
Table-1 Socio Demographic Profile

\begin{tabular}{|l|l|l|}
\hline Characteristics & No. of Women (n=200) & Incidence of CIN \% \\
\hline Age (years) mean \pm SD & & \\
$21-30$ & $34 \%$ & $17.6 \%$ \\
$31-40$ & $38 \%$ & $36.8 \%$ \\
$41-50$ & $22 \%$ & $54.5 \%$ \\
$51-60$ & $6 \%$ & $50 \%$ \\
\hline Age at first coitus (years) & & \\
mean \pm SD & $35 \%$ & $45 \%$ \\
$<15$ & $61 \%$ & $31 \%$ \\
$16-20$ & $4 \%$ & $25 \%$ \\
$>20$ & & \\
\hline Parity & $9 \%$ & $22.2 \%$ \\
$\mathrm{P}_{1}$ & $35 \%$ & $20 \%$ \\
$\mathrm{P}_{2}$ & $22 \%$ & $40.9 \%$ \\
$\mathrm{P}_{3}$ & $33 \%$ & $51.5 \%$ \\
$>\mathrm{P}_{3}$ & & \\
\hline Education & $30 \%$ & $43.5 \%$ \\
Literate & 705 & $31.4 \%$ \\
Illeterate & & \\
\hline Socioeconomic Status & $60 \%$ & $42.5 \%$ \\
Low & $30 \%$ & $27 \%$ \\
Middle & $10 \%$ & $31.3 \%$ \\
Upper & $10 \%$ & \\
\hline H/O contraceptive method & & $17.6 \%$ \\
uses & $4.5 \%$ & $12.8 \%$ \\
CU-T & $20 \%$ & $5.8 \%$ \\
OCP & $52.5 \%$ & $34.1 \%$ \\
Barrier & & \\
Permanent & & \\
Non user & & \\
\hline
\end{tabular}

Table-2 Correlation between cytology to VIA and VILI

\begin{tabular}{|l|l|l|l|l|l|}
\hline S. & Cytological & \multicolumn{3}{l|}{ VIA } & \multicolumn{2}{l|}{ VILI } \\
\cline { 3 - 6 } No. & Report & VIA +ve & $\mathbf{\%}$ & VILI +ve & \% \\
\hline 1 & Normal (n=13) & 1 & 8.23 & 1 & 7.69 \\
\hline 2 & Inflammation (n=112) & 58 & 51.89 & 27 & 24.10 \\
\hline 3 & ASCUS (n=18) & 11 & 61.11 & 9 & 50.50 \\
\hline 4. & LSIL (n=28) & 25 & 89.28 & 23 & 82.14 \\
\hline 5 & HSIL (n=27) & 26 & 96.29 & 26 & 96.29 \\
\hline 6 & Invasive Ca (n=2) & 2 & 100.0 & 2 & 100.0 \\
\hline Total & & $\mathbf{1 2 3}$ & $\mathbf{6 1 . 5}$ & $\mathbf{8 8}$ & $\mathbf{4 4 . 0}$ \\
\hline
\end{tabular}

$\chi 2=7.559 \quad \mathrm{p}<0.003 \quad$ Statistically Significant 
Colposcopic diagnosis of premalignant \& malignant lesions based on Reid's index were correlated with VIA \& VILI results which were statistically significant as shown in table 3.

Table -3 Correlation between Colposcopy to VIA and VILI

\begin{tabular}{|l|l|l|l|l|l|}
\hline \multirow{2}{*}{$\begin{array}{l}\text { S. } \\
\text { No. }\end{array}$} & \multirow{2}{*}{ Colposcopic Finding } & VIA & VILI \\
\cline { 3 - 6 } & & VIA +ve & $\mathbf{\%}$ & VILI +ve & $\mathbf{\%}$ \\
\hline 1 & Normal (n=31) & 2 & 6.45 & 1 & 3.22 \\
\hline 2 & Chronic Cervicitis (n=55) & 19 & 34.54 & 3 & 5.45 \\
\hline 3 & Sq. Metaplasia (n=24) & 15 & 62.5 & 5 & 20.83 \\
\hline 4. & CIN - I (n=41) & 41 & 100.0 & 40 & 97.56 \\
\hline 5 & CIN - II (n=32) & 31 & 96.87 & 32 & 100.0 \\
\hline 6 & CIN - III (n=4) & 4 & 100.0 & 4 & 100.0 \\
\hline 7 & Invasive Ca (n=2) & 2 & 100.0 & 2 & 100.0 \\
\hline 8 & Unsatisfactory (n=11) & 9 & 81.81 & 1 & 9.09 \\
\hline Total & & $\mathbf{1 2 3}$ & $\mathbf{6 1 . 5}$ & $\mathbf{8 8}$ & $\mathbf{4 4 . 0}$ \\
\hline
\end{tabular}

Lastly the results of VIA \& VILI were correlated with HPE report and sensitivity, specificity, PPV \& NPV of VIA \& VILI were estimated correlation is shown in table 4.

Table -4 Correlation between HPR finding to VIA and VILI

\begin{tabular}{|l|l|l|l|l|l|}
\hline \multirow{2}{*}{$\begin{array}{l}\text { No. } \\
\text { No }\end{array}$} & HPR Finding (n=136) & VIA & \multicolumn{2}{l|}{ VILI } \\
\cline { 3 - 6 } & VIA +ve & VIA -ve & VILI +ve & VILI -ve \\
\hline 1 & Normal (n=9) & 4 & 5 & 1 & 8 \\
\hline 2 & Inflammatory $(\mathrm{n}=63)$ & 40 & 23 & 23 & 40 \\
\hline 3 & Mild Dysplasia (n=36) & 35 & 1 & 34 & 02 \\
\hline 4. & Moderate dysplasia (n=21) & 20 & 1 & 21 & - \\
\hline 5 & Severe Dysplasia (n=5) & 5 & - & 5 & - \\
\hline 6 & Invasive Ca (n=2) & 2 & - & 2 & - \\
\hline Total & $\mathbf{1 0 6}$ & $\mathbf{3 0}$ & $\mathbf{8 6}$ & $\mathbf{5 0}$ \\
\hline
\end{tabular}

VIA when compared with HPR had sensitivity of $88.0 \%$ and specificity of $67.0 \%$ and corresponding PPV was 74.0\% \& NPV 84.0\%. VILI when compared with HPR had sensitivity of $80.0 \%$ and specificity of $95.87 \%$ and corresponding PPV was $95.0 \%$ and NPV 85.0\%. (Table 5)

Table 5 Summary of VIA and VILI study results

\begin{tabular}{|l|l|l|l|l|l|}
\hline S.No. & Authors & VIA & VILI \\
\cline { 3 - 6 } & & Sensitivity & Specificity & Sensitivity & Specificity \\
\hline 1 & $\begin{array}{l}\text { Shankarnarayan et al } \\
(2003)^{3}\end{array}$ & $88.6 \%$ & $78.0 \%$ & $87.2 \%$ & $86.5 \%$ \\
\hline 2 & Qureshi et al $4^{4}$ & $55.5 \%$ & $71.39 \%$ & $86.84 \%$ & $48.93 \%$ \\
\hline 3 & Shastri et al $(2005)^{5}$ & $59.7 \%$ & $88.4 \%$ & $75.4 \%$ & $84.3 \%$ \\
\hline
\end{tabular}

